\title{
Avaliação da atividade fungicida de extratos e óleos essenciais sobre ferrugem asiática da soja ${ }^{1}$
}

\author{
Evaluation of the fungicidal activity of extracts and essential oils on Asian soybean \\ rust
}

\author{
Daísa Bigaton ${ }^{2 *}$, Lilian Maria Arruda Bacchi ${ }^{3}$ Anelise Samara Nazari Formagio ${ }^{4}$, Walber Luiz Gavassoni ${ }^{3}$ e \\ Cláudia de Souza Zanella ${ }^{4}$
}

\begin{abstract}
RESUMO - Os extratos e óleos essenciais extraídos de plantas têm grande potencial no controle de fitopatógenos, por sua ação fungitóxica direta, inibindo o crescimento micelial e a germinação de esporos, e pela capacidade de induzir o acúmulo de fitoalexinas nas plantas. Objetivou-se com esse trabalho avaliar o efeito de diferentes extratos metanólicos e óleos essenciais sobre a ferrugem asiática da soja (Phakopsora pachyrhizi). O experimento foi realizado em casa-devegetação e sala de incubação. Utilizou-se o delineamento inteiramente casualizado com sete tratamentos e dez repetições. A cultivar de soja utilizada foi a BRS 245RR; os tratamentos constaram de óleos essenciais e extratos metanólicos dos gêneros Schinus terebinthifolius (aroeira-pimenteira), e Trichilia silvatica (quebra-machado, catiguá-vermelho), surfactante Tween 80 a $1 \%$ (v/v) e a testemunha água. As plantas foram pulverizadas com os respectivos tratamentos e inoculadas artificialmente com o fungo cerca de 24 horas depois. As características analisadas foram: número de folíolos/ parcela; índice de clorofila; altura de plantas; intensidade da ferrugem asiática da soja; número de folíolos com ferrugem; número de folíolos com aspecto queimado. As plantas pulverizadas com extrato de Schinus a 5\% (m/v) e óleo de Schinus a $1 \%$ (v/v) mostraram maior intensidade da doença, comparadas às pulverizadas com água. Estes dois tratamentos e o óleo de Trichilia a 1\% provocaram uma maior incidência de folíolos queimados, indicando fitotoxicidade à cultura.
\end{abstract}

Palavras-chave: Biocontrole. Fungicidas. Phakopsora pachyrhizi.

\begin{abstract}
Extracts and essential oils from plants have a great potential to control phytopathogens due to their direct fungitoxic action, inhibiting mycelial growth and spore germination, and their ability to induce the accumulation of phytoalexins in plants. The objective of this work was to evaluate the effect of different methanol extracts and essential oils on Asian soybean rust (Phakopsora pachyrhizi). The experiment was carried out in a green house and incubator. A completely randomized experimental design of seven treatments and ten replications was used. The soybean cultivar was BRS 245RR; the treatments consisted of essential oils and methanol extracts of the genus Schinus terebinthifolius (Brazilian pepper tree) and Trichilia silvatica (quebra-machado, catiguá-vermelho), the surfactant, Tween 80 (1\% v/v), and water, as a control. The plants were sprayed with their respective treatments, and then artificially inoculated with the fungus about 24 hours later. The characteristics analysed were: number of leaflets per plot; chlorophyll index, plant height, intensity of the Asian soybean rust, number of leaflets with rust, number of leaflets with a burnt appearance. The plants sprayed with $5 \%(\mathrm{~m} / \mathrm{v})$ Schinus extract, and $1 \%(\mathrm{v} / \mathrm{v})$ Schinus oil showed greater intensity of the disease compared to those sprayed with water. These two treatments and $1 \%$ Trichilia oil caused an increased incidence of burned leaflets, indicating phytotoxicity to the crop.
\end{abstract}

Key words: Biocontrol. Fungicides. Phakopsora pachyrhizi.

\footnotetext{
*Autor para correspondência

${ }^{1}$ Recebido para publicação em 18/05/2012; aprovado 21/02/2013

Trabalho desenvolvido por discentes do Programa de Pós-Graduação em Agronomia - Produção Vegetal, da UFGD

${ }^{2}$ Programa de Pós-Graduação em Agronomia da UFGD, Rodovia Dourados a Itahum Km 12, Caixa Postal 533, Dourados-MS, Brasil, 79.804-970, daisabig@omturbo.com

${ }^{3}$ Faculdade de Ciências Agrárias/UFGD, Dourados-MS, Brasil, lilianbacchi@ufgd.edu.br; walbergavassoni@ufgd.edu.br

${ }^{4}$ Faculdade de Ciências Agrárias/UFGD, Dourados-MS, Brasil, aneliseformagio@ufgd.edu.br, clauuzaza@gmail.com
} 


\section{INTRODUÇÃO}

As primeiras epidemias severas de ferrugem asiática da soja na América do Sul foram relatadas no Paraguai, na safra 2000/01, e no Brasil, na safra 2001/02, nas regiões sul do estado de Goiás, no Mato Grosso, norte do Mato Grosso do Sul e no Rio Grande do Sul (YORINORI et al., 2005). Em função de sua fácil disseminação pelo vento a ferrugem asiática pode ser encontrada em praticamente todas as regiões produtoras do Brasil causando reduções de até $75 \%$ de produtividade (ALMEIDA et al., 2005).

$\mathrm{O}$ uso intensivo e indiscriminado de defensivos agrícolas tem causado diversos problemas no meio ambiente como a contaminação de águas, solo, animais e alimentos; intoxicação de agricultores; eliminação de microrganismos responsáveis pela degradação de matéria orgânica ou de organismos utilizados em programas de controle biológico; e resistência de fitopatógenos, pragas e plantas daninhas a certos defensivos, entre outros. A exploração da atividade biológica de compostos secundários presentes em extrato ou óleo essencial de plantas pode se constituir em opção para reduzir com segurança o uso de defensivos (SCHWAN-ESTRADA; STANGARLIN; CRUZ, 2003).

Trabalhos que utilizaram extratos vegetais mostraram seu potencial no controle de fitopatógenos, por sua ação fungitóxica direta, inibindo o crescimento micelial e a germinação de esporos, e pela capacidade de induzir o acúmulo de fitoalexinas (SCHWANESTRADA; STANGARLIN; CRUZ, 2003; STANGARLIN et al., 1999).

Diversos autores têm trabalhado com controle alternativo de doenças entre eles Venturoso et al. (2011) que verificaram in vitro atividade antifúngica aos fitopatógenos Aspergillus sp., Penicillium sp., Colletotrichum sp., Phomopsis sp., Fusarium solani e Cercospora kikuchii, apenas com a utilização dos extratos aquosos de cravo-da-índia, alho e canela. Carnelossi et al. (2009) verificaram que os óleos essenciais de Cymbopogon citratus, Eucalyptus citriodora, Mentha arvensis e Artemísia dracunculus possuem potenciais no controle de Colletotrichum gloeosporioides em frutos de mamão. Silva e Bastos (2007) verificaram atividade antifúngica de óleos essenciais de Piper callosum, Piper marginatum var. anisatum e Piper enckea sobre Crinipellis perniciosa, Phytophthora palmivora e Phytophthora capsici.

Entre as plantas que apresentaram potencial antifúngico ou antimicrobiano encontram-se Schinus terebinthifolius e algumas espécies de Trichilia sp (ALADESANMI et al., 2007; GUNDIDZA et al., 2009; JOHANN et al., 2007; PINTO; SOUZA; OLIVEIRA,
2010; RHOUMA et al., 2009; SANTOS et al., 2010). Testando espécies de Pistacia e Schinus quanto ao seu efeito sobre fungos e bactérias fitopatogênicos, in vitro, Rhouma et al. (2009), detectaram maior atividade antifúngica em extratos de Schinus molle e S. terebinthifolius. Óleos essenciais das duas espécies de Schinus também inibiram os fungos fitopatogênicos Alternaria sp., Botrytis sp., Colletotrichum sp. e Fusarium sp., sendo que o óleo de S. terebinthifolius apresentou efeito fungicida mais pronunciado contra Botrytis sp. (SANTOS et al., 2010).

Objetivou-se com este trabalho avaliar o efeito de extratos e óleos essenciais de Schinus terebinthifolius e Trichilia silvatica sobre a ferrugem asiática da soja (Phakopsora pachyrhizi), em condições controladas.

\section{MATERIAL E MÉTODOS}

O experimento foi conduzido em casa de vegetação e sala de incubação do Laboratório de Microbiologia e Fitopatologia da Universidade Federal da Grande Dourados (UFGD), no município de Dourados - MS ( $22^{\circ} 16^{\prime}$ S e $54^{\circ} 49^{\prime} \mathrm{W}$ ) no período de 16/02/2011 a 14/04/2011. Os extratos vegetais e óleos essenciais foram obtidos no Laboratório de Plantas Medicinais da UFGD.

\section{Coleta do material vegetal}

Frutos de Schinus terebinthifolius (aroeirapimenteira) foram coletados no Horto de Plantas Medicinais da UFGD e folhas de Trichilia silvatica (quebra-machado; catiguá-vermelho) próximas à cidade de Dourados. As plantas foram identificadas pela professora Dr. Zefa Valdevina Pereira - UFGD. Exsicatas de $S$. terebinthifolius e T. silvatica foram depositadas no herbário da Faculdade de Ciências Biológicas da UFGD (DDMS 4602 e DDMS4662), respectivamente.

\section{Preparação do extrato}

O material vegetal foi desidratado em estufa de ar circulante a $45{ }^{\circ} \mathrm{C}$ (AC-035/81), durante quatro dias. Após secagem, foi triturado em moinho de facas (MA340/A) (260 g) e submetido a extração por maceração com metanol $(5 \times 250 \mathrm{~mL})$ absoluto e posteriormente filtrado e concentrado em evaporador rotativo (MA-120) sob pressão reduzida e posterior liofilização para obtenção dos extratos metanólicos $S$. terebinthifolius $(15 \mathrm{~g})$ e $T$. silvatica $(10 \mathrm{~g})$.

\section{Extração do óleo essencial}

A extração do óleo essencial foi realizada com as folhas frescas de T. silvatica (200g) e frutos frescos e maduros de S. terebinthifolius (200g) por hidrodestilação em aparelho 
modificado de Clevenger por 4 horas. O óleo essencial foi extraído com hexano, seco com sulfato de sódio anidro e armazenado $-10^{\circ} \mathrm{C}$ para posteriores análises. $\mathrm{O}$ rendimento do óleo obtido foi calculado em função do volume de óleo obtido e do peso de material vegetal fresco.

\section{Cultivo das plantas de soja}

Foram semeadas, quatro sementes de soja cultivar BRS 245 RR por vaso, e após cinco dias da emergência das plântulas foi realizado o desbaste, deixando-se uma plântula por vaso. Os vasos plásticos continham $674 \mathrm{~g}$ de terra retirada de um Latossolo Vermelho Distroférrico, na camada de 0 a $20 \mathrm{~cm}$ com as seguintes características: $\mathrm{pH}\left(\mathrm{em}_{2} \mathrm{O}\right)=5,2 ; \mathrm{Al}$ trocável $\left(\mathrm{cmol}_{\mathrm{c}} \mathrm{dm}^{-3}\right)=0,8 ; \mathrm{Ca}+\mathrm{Mg}\left(\mathrm{cmol}_{\mathrm{c}} \mathrm{dm}^{-3}\right)=$ 1,60; P - Mehlich $1\left(\mathrm{mg} \mathrm{dm}^{-3}\right)=0,8 ; \mathrm{K}\left(\mathrm{mg} \mathrm{dm}^{-3}\right)=$ 0,$08 ;$ Matéria orgânica $=10,16 \mathrm{~g} \mathrm{~kg}^{-1} ; \mathrm{V}(\%)=19 ; \mathrm{m}$ $(\%)=32$; Soma de bases $=1,68\left(\mathrm{cmol}_{\mathrm{c}} \mathrm{dm}^{-3}\right)$; CTCt $=8,9\left(\mathrm{cmol} \mathrm{dm}^{-3}\right) ;$ CTCe $=2,5\left(\mathrm{cmol} \mathrm{dm}^{-3}\right)$; argila $=872 \mathrm{~g} \mathrm{~kg}^{-1}$; silte $=94 \mathrm{~g} \mathrm{~kg}^{-1} \mathrm{e}$ areia $=34 \mathrm{~g} \mathrm{~kg}^{-1}$; que foi adubada com adubo 00-20-20. O tratamento das sementes foi realizado antes da semeadura com a mistura carbendazim + thiram (200 ml p.c./100 kg de sementes).

\section{Aplicação dos tratamentos}

Os tratamentos foram: (1) óleo essencial de $S$. terebinthifolius a $1 \%(\mathrm{v} / \mathrm{v}) ;(2)$ extrato de S. terebinthifolius a $1 \%(\mathrm{~m} / \mathrm{v}) ;(3)$ extrato de $S$. terebinthifolius a $5 \%(\mathrm{~m} / \mathrm{v})$; (4) óleo essencial de T. silvatica a $1 \%(\mathrm{v} / \mathrm{v})$; (5) extrato de $T$. silvatica a $1 \%(\mathrm{~m} / \mathrm{v}) ;(6)$ surfactante Polysorbate 80 (Tween 80) a 1\%; (7) água. Óleos e extratos foram misturados em $100 \mathrm{ml}$ de água destilada e posteriormente aplicados sobre todas as plantas, utilizando-se pulverizador manual com gatilho para garrafa PET. Para dissolver completamente os extratos, utilizou-se o surfactante Tween (1\%). As plantas foram pulverizadas com os tratamentos aos 41 dias após a semeadura.

\section{Inoculação de Phakopsora pachyrhizi}

Vinte e quatro horas após os tratamentos, a inoculação foi feita pela pulverização manual de suspensão de esporos de Phakopsora pachyrhizi que se encontravam em nitrogênio líquido; as plantas foram envolvidas com plástico por $12 \mathrm{~h}$ para manutenção da umidade sobre as folhas, e após esse período foram colocadas em câmara de incubação até as avaliações.

\section{Avaliações}

As variáveis avaliadas foram: número de folíolos por parcela; índice de clorofila; altura de plantas; intensidade da ferrugem asiática da soja; número de folíolos com ferrugem; porcentagem de folíolos com aspecto queimado. Para avaliação da intensidade da ferrugem asiática, foi utilizada uma escala diagramática para níveis de severidade da doença (GODOY; KOGA; CANTERI, 2006). Para o índice de clorofila foi utilizado um clorofilômetro portátil (SPAD - Soil Plant Analisis Development).

\section{Delineamento experimental e análise estatística}

As parcelas experimentais foram arranjadas em delineamento inteiramente casualizado com sete tratamentos e dez repetições; os dados foram submetidos à análise de variância e as médias comparadas pelo teste de Duncan a $5 \%$.

\section{RESULTADOS E DISCUSSÃO}

Os tratamentos com extrato e óleo essencial de quebra-machado (Trichilia silvatica) e extrato de aroeirapimenteira (Schinus terebinthifolius) a 5\% reduziram o número de folíolos em relação ao tratamento com água. Os extratos de T. silvatica (1\%) e S. terebinthifolius a 5\% também diferiram do tratamento com Tween, descartando a possibilidade do efeito na redução do número de folíolos ser devido ao surfactante utilizado para dissolver os mesmos. Quanto ao índice de clorofila, não houve diferença estatística. As plantas de soja pulverizadas com óleo essencial de aroeira-pimenteira apresentaram maior altura diferindo estatisticamente dos tratamentos com extratos de aroeirapimenteira ( $1 \%$ e $5 \%$ ) e quebra-machado (Tabela 1$)$.

Efeito de extratos de plantas sobre o desenvolvimento de plantas adultas também foi observado por Dequech et al. (2008), que obtiveram uma menor produtividade de feijãovagem em plantas tratadas com extratos aquosos de folhas de jambolão (Syzygium cuminii) e frutos maduros de nim (Azadirachta indica), utilizados para o controle de insetos.

Atividade alelopática de $S$. terebinthifolius foi também observada por Comiotto, Moraes e Lopes (2011) com sementes e plântulas de alface. Em seu trabalho, extratos aquosos de folhas de aroeira-pimenteira na concentração de $50 \%(\mathrm{~m} / \mathrm{v})$ reduziram a porcentagem de germinação, o índice de velocidade de germinação e resultaram em redução no comprimento e na massa fresca de plântulas.

Os extratos e óleos essenciais de aroeira-pimenteira e quebra-machado não controlaram Phakopsora pachyrhizi. Ao contrário, as plantas pulverizadas com extrato de aroeira-pimenteira a 5\% e óleo essencial da mesma espécie a $1 \%$ mostraram maior intensidade da doença, comparadas às pulverizadas com água (Tabela 1).

Outros autores também observaram um aumento na atividade de fungos fitopatogênicos, ainda que in vitro, em resposta a aplicação de extratos de plantas. Pinto, Souza e Oliveira (2010) usaram extratos metanólicos de plantas a fim de controlar antracnose do feijoeiro; dos 300 extratos 
Tabela 1 - Características avaliadas em soja variedade BRS 245RR, após a aplicação de óleos essenciais e extratos vegetais

\begin{tabular}{lcccc}
\hline \multicolumn{1}{c}{ Tratamento } & Número de folíolos & Índice de clorofila & Altura de planta & Severidade ferrugem asiática (\%) \\
\hline Água & $42,90 \mathrm{a}$ & $30,47 \mathrm{a}$ & $53,10 \mathrm{ab}$ & $1,42 \mathrm{~b}$ \\
Tween $80-1 \%$ & $42,00 \mathrm{ab}$ & $32,90 \mathrm{a}$ & $53,10 \mathrm{ab}$ & $2,03 \mathrm{ab}$ \\
Aroeira-pimenteira-óleo 1\% & $37,80 \mathrm{abc}$ & $32,26 \mathrm{a}$ & $58,80 \mathrm{a}$ & $2,82 \mathrm{a}$ \\
Quebra-machado-óleo 1\% & $36,60 \mathrm{bc}$ & $32,96 \mathrm{a}$ & $55,80 \mathrm{ab}$ & $1,73 \mathrm{ab}$ \\
Aroeira-pimenteira-extrato 1\% & $36,90 \mathrm{abc}$ & $30,67 \mathrm{a}$ & $50,55 \mathrm{~b}$ & $2,26 \mathrm{ab}$ \\
Quebra-machado-extrato 1\% & $35,70 \mathrm{c}$ & $31,26 \mathrm{a}$ & $49,33 \mathrm{~b}$ & $2,62 \mathrm{ab}$ \\
Aroeira-pimenteira-extrato 5\% & $35,10 \mathrm{c}$ & $31,18 \mathrm{a}$ & $49,90 \mathrm{~b}$ & $2,97 \mathrm{a}$ \\
CV $(\%)$ & 16,62 & 13,13 & 14,76 & 28,73 \\
\hline
\end{tabular}

Médias com a mesma letra minúscula na coluna não diferem entre si pelo teste de Duncan a 5\%

utilizados apenas 13 inibiram eficientemente Colletotrichum lindemuthianum, entre eles Trichilia pallida. Embora o extrato de T. pallida tenha ocasionado inibição do crescimento micelial e na germinação dos esporos do fungo, não resultou em controle de antracnose do feijoeiro, in vivo.

Trés et al. (2010) com o intuito de obter resultado no controle de Phakopsora pachyrhizi utilizaram in vitro extratos de penicilina e cavalinha, e concluíram que essas plantas são potenciais para serem testadas a campo, porém a dose de 5\%, para ambas, estimulou a germinação dos esporos da ferrugem asiática da soja.

Medice et al. (2007) avaliando o efeito in vivo e in vitro de diferentes óleos essenciais sobre o fungo Phakopsora pachyrhizi verificaram que in vivo, quando avaliaram a severidade da doença com base no número de pústulas por $\mathrm{cm}^{2}$, todos os óleos aplicados tiveram efeito no controle da doença. In vitro, os óleos essenciais de Eucalyptus citriodora (eucalipto citriodora), Cymbopogon nardus (citronela), Azadiradhta indica (nim) e Thymus vulgaris L. (tomilho) nas concentrações de $1,0,5,1$ e $0,3 \%(\mathrm{v} / \mathrm{v})$, respectivamente, interferiram na germinação dos uredosporos do fungo.

Yamashita et al. (2011) testaram capim cidreira (Cymbopogon citratus) como controle alternativo de Phakopsora pachyrhizi e observaram que seus extratos são promissores para testes que visam o controle da ferrugem asiática da soja. Extratos aquosos de folhas de timborno (Himatanthus articulatus), jurema preta (Mimosa bimucronata), tamboril (Entorolobium contortisiliquum), peroba (Aspidiosperma polyneuron) e de nim reduziram significativamente a germinação de uredosporos de $P$. pachyrhizi (COSTA; COIMBRA; SANTOS, 2010).

Mesquini et al. (2011) avaliaram o controle e o progresso da ferrugem asiática, em condições de campo, quando submetida aos tratamentos com produtos alternativos. Aos 123 dias após a semeadura, o tratamento com óleo essencial de E. citriodora apresentou índice de $61 \%$ de controle, diferindo do tratamento com fungicida, que apresentou $99 \%$ de controle da doença. No entanto, mesmo que o controle proporcionado pelos extratos de plantas seja inferior ao tratamento com fungicida, seu uso permite contribuir para o manejo da doença nos casos em que os fungicidas convencionais não são permitidos, como na agricultura orgânica.

Óleo essencial e extratos de folhas de Eremanthus erythropappus (candeia) inibiram completamente a germinação de uredosporos de Hemileia vastatrix, Puccinia psidii, Phakopsora pachyrhizi e Cerotelium fici, destacando-se o potencial dessa espécie para o controle de ferrugens (SALUSTIANO et al., 2006).

Foi verificada maior incidência de folíolos queimados nos tratamentos com aroeira-pimenteiraóleo e extrato 5\%; e quebra-machado-óleo; indicando fitotoxicidade à cultura (Tabela 2). Aos dois dias após a aplicação do tratamento, apenas as plantas pulverizadas com óleo essencial de aroeira-pimenteira apresentavam uma maior porcentagem de folíolos com aspectos queimados, comparadas às plantas pulverizadas com água. Porém, na avaliação realizada aos oito dias após os tratamentos, as plantas que foram tratadas com óleo essencial de quebra-machado e com extrato de aroeira-pimenteira na maior concentração, também apresentaram os sintomas de fitotoxicidade (Tabela 2).

Sintomas semelhantes aos observados sobre plantas de soja (Figura 1), neste trabalho, foram relatados e registrados por Barreto, Araújo e Bonifácio (2010) em plantas de algodoeiro tratadas com extratos de Agave sisalana, utilizados para o controle de ácaro rajado. Extratos aquosos a $10 \%(\mathrm{~m} / \mathrm{v})$ de pó-de-fumo (Nicotiana tabacum) e um produto comercial à base de frutos de nim (Azadirachta indica) a $10 \%$ foram fitotóxicos a feijoeiro 
Tabela 2 - Porcentagem de folíolos queimados na variedade de soja BRS 245RR aos dois e oito dias após a aplicação de óleos essenciais e extratos vegetais

\begin{tabular}{lcc}
\hline \multicolumn{1}{c}{ Tratamentos } & \% Folíolos queimados aos 2 dias & \% Folíolos queimados aos 8 dias \\
\hline Água & $0,00 \mathrm{~b}$ & $0,06 \mathrm{c}$ \\
Tween $80-1 \%$ & $0,00 \mathrm{~b}$ & $0,19 \mathrm{c}$ \\
Aroeira-pimenteira-óleo $1 \%$ & $2,44 \mathrm{a}$ & $18,76 \mathrm{a}$ \\
Quebra-machado-óleo 1\% & $1,58 \mathrm{ab}$ & $20,02 \mathrm{a}$ \\
Aroeira-pimenteira-extrato $1 \%$ & $0,00 \mathrm{~b}$ & $1,61 \mathrm{bc}$ \\
Quebra-machado-extrato 1\% & $0,42 \mathrm{ab}$ & $3,68 \mathrm{bc}$ \\
Aroeira-pimenteira-extrato 5\% & $0,00 \mathrm{~b}$ & $10,25 \mathrm{ab}$ \\
CV $(\%)$ & 260,25 & 96,63 \\
\hline
\end{tabular}

Médias com a mesma letra minúscula na coluna não diferem entre si pelo teste de Duncan a 5\%

Figura 1 - Aspecto das folhas queimadas após a aplicação de óleos essenciais e extratos vegetais das plantas aroeira-pimenteira e quebra-machado
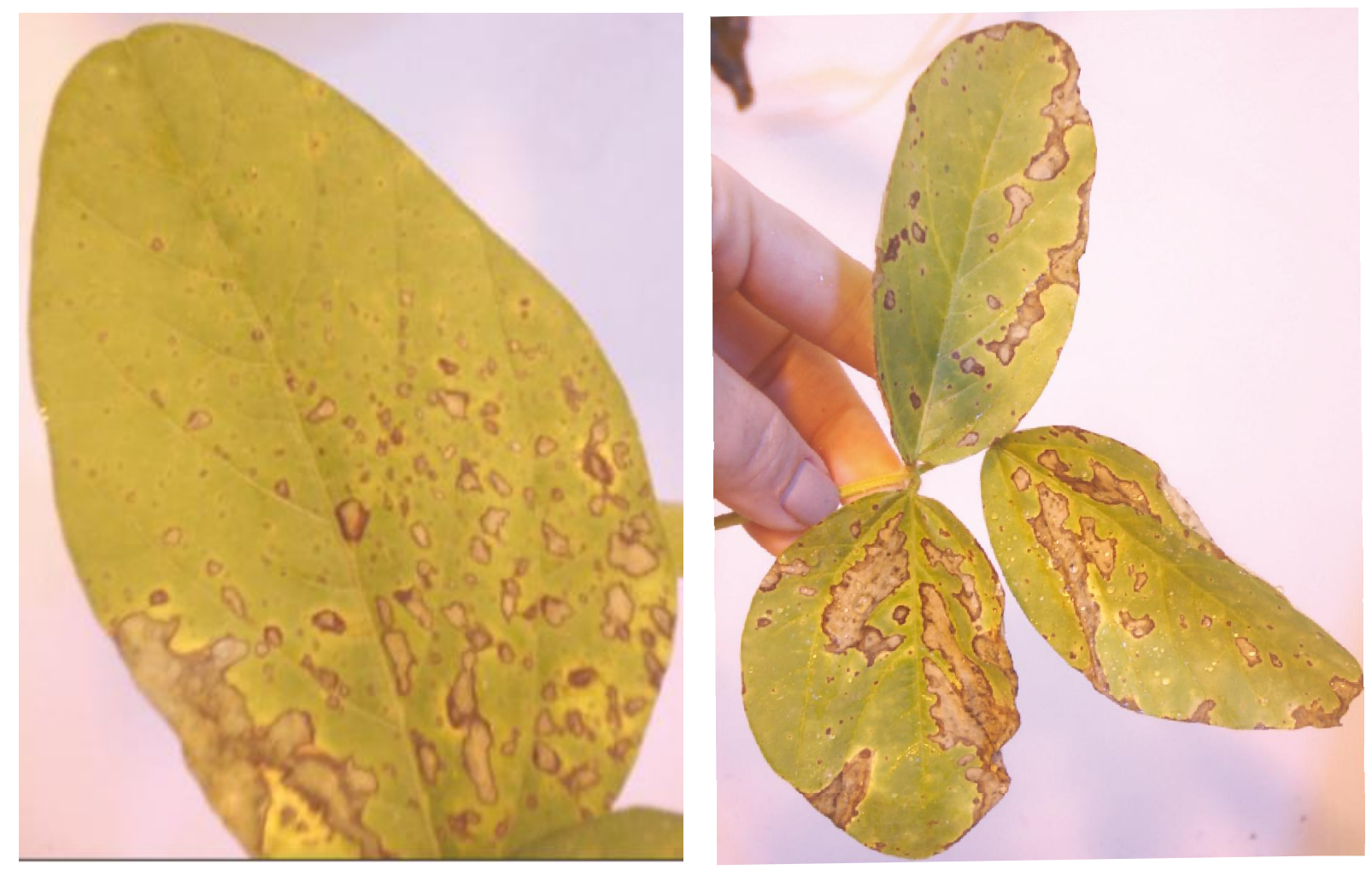

(DEQUECH et al., 2008). O uso de extrato de pó-de-fumo resultou em menor fitotoxicidade com leve descoloração e atrofia, enquanto que o produto formulado com nim provocou escurecimento das nervuras e bronzeamento de diversos pontos do limbo foliar.

Embora extrato e óleo essencial de aroeirapimenteira não tenham controlado $P$. pachyrhizi, outros resultados indicaram moderada atividade do óleo essencial de folhas frescas contra quatro espécies de fungos, em trabalho desenvolvido na África (GUNDIDZA et al., 2009). Os autores sugerem que a ação antifúngica do óleo essencial de $S$. terebinthifolius seja proporcionada pela alta concentração de monoterpenos. El-Massry et al. (2009) observaram efeito antifúngico de extrato etanólico e óleo essencial de folhas de $S$. terebinthifolius cultivado no Egito. 
Neste trabalho foram utilizados frutos de $S$. terebinthifolius para a obtenção de extrato e óleo essencial. Segundo Nazari Formagio et al. (2011), foram identificados 18 compostos em óleo essencial de frutos de aroeira-pimenteira, no Brasil, com predominância de monoterpenos, e embora a composição encontrada tenha diferido da relatada por outros autores, o principal constituinte foi $\beta$-pineno. O composto monoterpeno encontrado em maior quantidade por Gundidza et al. (2009) foi $\alpha$-pineno.

Segundo Gundidza et al. (2009), diferenças na composição química de $S$. terebinthifolius desenvolvendo-se em diferentes países ou regiões podem justificar as diferenças encontradas quanto as suas atividades antibacteriana, antifúngica e antioxidante que se devem ao efeito sinergístico de seus constituintes.

Da mesma forma, Formagio et al. (2012) concluem que a composição química do óleo essencial obtido de Trichilia silvatica de Mato Grosso do Sul difere da encontrada em óleos essenciais da mesma espécie originária de outras regiões do Brasil, devido às diferenças nutricionais e de suprimento de água e luz. O óleo essencial de T. silvatica foi caracterizado por um grande número de compostos sesquiterpenos (FORMAGIO et al., 2012; SOUZA, 2008). No extrato etanólico das folhas de T. silvatica foram identificados o $\alpha$-tocoferol, quatro compostos sesquiterpenos, o esteróide $\beta$-sitosterol e uma mistura contendo quatro triterpenos (SOUZA, 2008). Em extratos metanólicos desta espécie foram isolados os esteróides $\beta$-sitosterol e estigmasterol, sesquiterpenos e a cumarina escopoletina (FIGUEIREDO, 2010).

\section{CONCLUSÃO}

Plantas de soja tratadas com extrato metanólico a $5 \%$ e óleo essencial a $1 \%$ de Schinus terebinthifolius apresentaram maior intensidade de ferrugem asiática da soja, quando comparados à testemunha. Esses dois tratamentos e o óleo essencial de Trichilia silvatica a $1 \%$ apresentaram-se tóxicos à cultura.

\section{AGRADECIMENTOS}

À CAPES pela bolsa concedida à primeira autora.

\section{REFERÊNCIAS}

ALADESANMI, A. J. et al. Antimicrobial and antioxidant activities of some Nigerian medicinal plants. African Journal Traditional CAM, v. 4, n. 2, p. 173-184, 2007.
ALMEIDA, A. M. R. et al. Doenças da soja (Glycine max). In: KIMATI, H. et al. (Ed.). Manual de Fitopatologia. Doenças das Plantas Cultivadas. 4. ed. São Paulo: Agronômica Ceres, 2005. p. 569-588. v. 2.

BARRETO, A. F.; ARAÚJO, E.; BONIFÁCIO, B. F. Eficiência de extratos de Agave sisalana (Perrine) sobre o ácaro rajado Tetranychus urticae (Koch) e ocorrência de fitotoxidez em plantas de algodoeiro (Gossypium hirsutum L. r latifolium Hutch). Revista Brasileira de Agroecologia, v. 5, n. 2, p. 207-215, 2010.

CARNELOSSI, P. R. et al. Óleos essenciais no controle póscolheita de Colletotrichum gloeosporioides em mamão. Revista Brasileira de Plantas Medicinais, v. 11, n. 4, p. 399-406, 2009.

COMIOTTO, A.; MORAES, D. M.; LOPES, N. F. Potencial alelopático de extratos aquosos de aroeira sobre germinação e crescimento de plântulas de alface. Scientia Agrária Paranaensis, v. 10, n. 3, p. 23-31, 2011.

COSTA, S. X.; COIMBRA, J. L.; SANTOS, F. da S. Efeito de extratos obtidos de plantas do cerrado baiano sobre a germinação de uredosporos de Phakopsora pachyrhizi. Magistra, v. 22, n. 1, p. 71-74, 2010.

DEQUECH, S. T. B. et al. Fitotoxicidade causada por inseticidas botânicos em feijão-de-vagem (Phaseolus vulgaris L.) cultivado em estufa plástica. Revista da FZVA, v. 15, n. 1, p. 71-80, 2008.

EL-MASSRY, K. F. et al. Chemical compositions and antioxidant/ antimicrobial activities of various samples prepared from Schinus terebinthifolius leaves cultivated in Egypt. Journal of Agricultural and Food Chemistry, v. 57, n. 12, p. 5265-5270, 2009.

FIGUEIREDO, E. R. Estudo fitoquímico e avaliação biológica dos extratos de Trichilia casaretti e Trichilia silvatica (Meliaceae). 2010. $150 \mathrm{f}$. Tese (Doutorado em Produção Vegetal) - Centro de Ciências e Tecnologias Agropecuárias, Universidade Federal do Norte Fluminense, Campo dos Goytacazes, 2010.

FORMAGIO, A. S. N. et al. Free radical scavenging and antiedematogenic activities of essential oil obtained from Trichilia silvatica DC. (Meliaceae) leaves. Latin American Journal of Pharmacy, v. 31, n. 3, p. 469-473, 2012.

GODOY, C. V.; KOGA, L. J.; CANTERI, M. G. Diagrammatic scale for assessment of soybean rust severity. Fitopatologia Brasileira, v. 31, n. 1, p. 63-68, 2006.

GUNDIDZA, M. et al. The chemical composition and biological activities of essential oil from the fresh leaves of Schinus terebinthifolius from Zimbabwe. African Journal of Biotechnology, v. 8, n. 24, p. 7164-7169, 2009.

JOHANN, S. et al. Antifungal properties of plants used in brazilian traditional medicine against clinically relevant fungal pathogens. Brazilian Journal of Microbiology, v. 38, n. 4, p. 632-637, 2007.

MEDICE, R. et al. Óleos essenciais no controle da ferrugem asiática da soja Phakopsora pachyrhizi Syd. \& P. Syd. Ciência e Agrotecnologia, v. 31, n. 1, p. 83-90, 2007.

MESQUINI, R. M. et al. Controle e progresso temporal da ferrugem asiática da soja sob controle alternativo em campo. Summa Phytopathologica, v. 37, n. 1, p. 24-29, 2011. 
MILANESI, P. M. et al. Ação fungitóxica de extratos vegetais sobre o crescimento micelial de Colletotrichum gloeosporioides. Revista da FZVA, v. 16, n. 1, p. 01-13, 2009.

NAZARI FORMAGIO, A. S. et al. Chemical composition and anti-inflammatory activity of the essential oil of Schinus terebinthifolius Raddi (Anacardiacea) fruits. Latin American Journal of Pharmacy, v. 30, n. 8, p. 1555-1559, 2011.

PINTO, J. M. A.; SOUZA, E. A.; OLIVEIRA, D. F. Use of plant extracts in the control of common bean anthracnose. Crop Protection, v. 29, n. 8, p. 838-842, 2010.

RHOUMA, A. et al. Antimicrobial activities of leaf extracts of Pistacia and Schinus species against some plant pathogenic fungi and bacteria. Journal of Plant Pathology, v. 91, n. 2, p. 339-345, 2009.

SALUSTIANO, M. E. et al. Extratos de candeia (Eremanthus erythropappus (DC.) Mac Leish) na inibição in vitro de Cylindrocladium scoparium e de quatro espécies de ferrugens. Cerne, v. 12, n. 2, p. 189-193, 2006.

SANTOS, A. C. A. et al. Efeito fungicida dos óleos essenciais de Schinus molle L. e Schinus terebinthifolius Raddi, Anacardiaceae, do Rio Grande do Sul. Revista Brasileira de Farmacognosia, v. 20, n. 2, p. 154-159, 2010.

SCHWAN-ESTRADA, K. R. F.; STANGARLIN, J. R.; CRUZ, M.

E. da S. Uso de plantas medicinais no controle de doenças de plantas. Fitopatologia Brasileira, v. 28, p. 54-56, 2003. Suplemento.
SILVA, D. M. M. H.; BASTOS, C. N. Atividade antifúngica de óleos essenciais de espécies de Piper sobre Crinipellis perniciosa, Phytophthora palmivora e Phytophthora capsici. Fitopatologia Brasileira, v. 32, n. 2, p. 143-145, 2007.

SOUZA, P. R. T. de Terpenos isolados de Trichilia casaretti e Trichilia silvatica (Meliaceae). 2008. 117 f. Dissertação (Mestrado em Química) - Universidade Estadual do Sudoeste da Bahia, Jequié, 2008.

STANGARLIN, J. R. et al. Plantas medicinais e controle alternativo de fitopatógenos. Biotecnologia Ciência \& Desenvolvimento, v. 11, p. 16-21, 1999.

TRÉS, S. P. et al. Penicilina e cavalinha no controle alternativo da ferrugem asiática da soja. Cascavel, v. 3, n. 4, p. 16-23, 2010.

VENTUROSO, L. dos R. et al. Atividade antifúngica de extratos vegetais sobre o desenvolvimento de fitopatógenos. Summa Phytopathologica, v. 37, n. 1, p. 18-23, 2011.

YAMASHITA, P. A. et al. Inibição da germinação de esporos da ferrugem asiática da soja por extratos de capim cidreira. In: CONGRESSO BRASILEIRO DE FITOPATOLOGIA, 44., 2011, Bento Gonçalves. Anais... Bento Gonçalves, 2011. 1 CD-ROM.

YORINORI, J. T. et al. Epidemics of Soybean Rust (Phakopsora pachyrhizi) in Brazil and Paraguay from 2001 to 2003. Plant Disease, v. 89, n. 6, p. 675-677, 2005. 